\title{
O Progresso do Tocantins: capítulos para além do Maranhão ${ }^{1}$
}

\author{
Thays ASSUNÇÃO ${ }^{2}$ \\ Rodrigo Nascimento REIS ${ }^{3}$
}

\begin{abstract}
Resumo:
Quando ainda havia indefinições sobre onde seria a capital do mais recente estado brasileiro, o Tocantins, o jornal O Progresso, situado na cidade de Imperatriz (no sudoeste do Maranhão), apostou que Araguaína teria condições de ser escolhida como capital, por isso fundou lá, em 1990, um impresso intitulado O Progresso do Tocantins. Este artigo, portanto, registra tal iniciativa editorial, buscando compreender essa expansão, suas características e motivos do encerramento. Por meio de pesquisa bibliográfica, entrevistas e análise documental, percebe-se como a situação geográfica, política e econômica pode interferir na fundação de um veículo. Além disso, o modo como O Progresso do Tocantins investiu em Araguaína fez do veículo um importante vetor de comunicação regional, atraindo a atenção de políticos e empresários.
\end{abstract}

Palavras-chave: jornalismo regional; O Progresso do Tocantins; história; imprensa .

Abstract:

\section{O Progresso do Tocantins: chapters beyond Maranhão}

When there was still no definition of where the capital would be of the most recent Brazilian state, Tocantins, the newspaper $O$ Progresso located in the city of Imperatriz (in the southwest of Maranhão) bet that Araguaína would be able to be chosen as capital and so he founded there in 1990 a newspaper entitled O Progresso do Tocantins. This article, therefore, records this editorial initiative seeking to understand this expansion, its characteristics and reasons for the closure. Through bibliographic research, interviews and document analysis, it is perceived how the geographical, political and economic situation can interfere in the foundation of a vehicle. In addition, the way $O$ Progresso do Tocantins invested in Araguaína made the vehicle an important vector of regional communication attracting the attention of politicians and businessmen.

Keywords: regional journalism; O Progresso do Tocantins; history; press.

Resumen:

\section{O Progresso do Tocantins: capítulos más allá de Maranhão}

Cuando todavía no había una definición de dónde estaría la capital del estado brasileño más reciente, Tocantins, el periódico $O$ Progresso ubicado en la ciudad de Imperatriz (en el suroeste de Maranhão) apostó a que Araguaína podría ser elegida como capital y es por eso que se fundado en 1990 un periódico titulado O Progresso do Tocantins. Este artículo, por lo tanto, registra esta iniciativa editorial que busca comprender esta expansión, sus características y razones para el cierre. A través de la investigación bibliográfica, entrevistas y análisis de documentos, se percibe cómo la situación geográfica, política y económica puede interferir en la fundación de un

\footnotetext{
${ }^{1}$ Uma versão preliminar deste artigo foi apresentado no XIII Encontro Nacional de História da Mídia realizado de forma on-line pela Universidade Federal de Juiz de Fora, entre 18 e 20 de agosto de 2021.

${ }^{2}$ Doutoranda pelo programa de Pós-Graduação em Comunicação da Universidade do Estado do Rio de Janeiro (PPGCOM/UERJ). Professora do curso de Jornalismo da Universidade Federal do Tocantins (UFT). E-mail: thays.jornalista@gmail.com

3 Doutorando pelo Programa de Pós-Graduação em Comunicação da Universidade Federal Fluminense (PPGCOM/UFF). É bolsista Nota 10 da Fundação Carlos Chagas Filho de Amparo à Pesquisa do Estado do Rio de Janeiro - FAPERJ. E-mail: rodrigoreisitz@gmail.com
} 
vehículo. Además, la forma en que $O$ Progresso do Tocantins invirtió en Araguaína convirtió al vehículo en un importante vector de comunicación regional que atrajo la atención de políticos y empresarios

Palabras clave: periodismo regional; O Progresso do Tocantins; historia; prensa.

\section{Introdução}

A década de 1970 inaugura em Imperatriz (Maranhão) um novo tempo. A cidade, antes considerada "Sibéria Maranhense", passa a receber pessoas de diferentes lugares do país e vários empreendimentos. A construção de estradas e, principalmente, da rodovia Belém-Brasília possibilita a saída de Imperatriz da condição de isolamento territorial, e sua respectiva projeção como um dos principais municípios do Estado (REIS, 2018).

Segundo Franklin (2008), a implantação das Centrais Elétricas do Maranhão (Cemar) e a expansão do ciclo econômico da madeira contribuem para que Imperatriz experimente na década de 1970 seu maior crescimento econômico e populacional. "Nesse período, a população saltou de 80.827 habitantes, contados pelo IBGE em 1970, para 220.469, totalizados pelo Censo de 1980" (FRANKLIN, 2008, p. 143).

Como parte desse processo de desenvolvimento, Imperatriz incrementa seus veículos jornalísticos. São instaladas as primeiras emissoras de rádio e televisão, e criados novos jornais no município. Dentre os impressos fundados nesse contexto, O Progresso é com certeza um dos mais relevantes para a história da imprensa imperatrizense.

Fundado em 3 de maio de 1970 pelo empresário gráfico José Matos Vieira e pelo jornalista Jurivê de Macedo, O Progresso é o impresso mais antigo em circulação de Imperatriz, com 51 anos em 2021. Em seus primeiros anos, era semanal - circulava aos domingos -, possuía quatro páginas e tinha formato $32 \times 43 \mathrm{~cm}$ (SANCHES, 2002). Posteriormente, o jornal passou a ser bissemanal, e, em 1979, tornou-se diário, variando entre oito e 12 páginas (CARVALHO, 2016).

Até o fim de 2021, O Progresso circulava de terça-feira a domingo com 16 páginas divididas em dois cadernos e oito editorias: Política, Polícia, Cidade, Regional, Esporte, Geral, Justiça e Tocantins. Na edição de final de semana, o impresso chega a possuir 30 páginas, devido à presença do suplemento literário Extra e do Caderno de Domingo. A tiragem do impresso, conforme informações no site do veículo, é de 5.300 mil exemplares de terça-feira a sábado. 
Quanto à administração do diário, ela é formada por Sergio Antonio Godinho (presidente e proprietário), Sergio Henrique Godinho (diretor superintendente) e Illya Nathasje (diretor comercial). O veículo possui uma equipe de reportagem constituída por três profissionais, conforme consta no expediente: o editor-chefe, Coriolano Miranda Rocha Filho; o repórter especializado na editoria de Polícia e Esporte, Dema de Oliveira; e o repórter e colunista William Marinho.

Um dos aspectos pertinentes a considerar sobre O Progresso é o seu alcance e produção regional. Ele é distribuído tanto em Imperatriz como em municípios do oeste do Maranhão e do norte do Tocantins, mais precisamente na região do Bico do Papagaio. Além disso, o impresso já apresentou ao longo de sua trajetória iniciativas mais arrojadas de regionalização. É o caso dos jornais O Progresso do Tocantins, fundado em Araguaína (TO) em 1990, e o Diário Tocantinense, criado em Palmas (TO) em 1997.

A descoberta da existência desses títulos motivou a realização do presente artigo especificamente sobre $O$ Progresso do Tocantins, visto que o veículo circulou em Araguaína durante sete anos (entre 1990 e 1997). Nosso objetivo é registrar, ainda que de forma introdutória, a experiência do jornal O Progresso no estado vizinho, destacando as motivações para criação e encerramento das atividades do jornal, assim como sua produção jornalística e características editoriais.

Para alcançar o objetivo deste trabalho, construímos um arcabouço metodológico formado por: 1) pesquisa bibliográfica, 2) entrevistas e 3) análise documental. A pesquisa bibliográfica se fez necessária para revisar as principais obras sobre a história de Imperatriz e jornalismo regional. As entrevistas foram realizadas em fevereiro de 2019 com o proprietário do jornal O Progresso (Sérgio Antonio Godinho) ${ }^{4}$ e o diretor comercial (Illya Nathasje) ${ }^{5}$ para entender a criação e o funcionamento do impresso. E a análise documental consistiu na consulta aos primeiros exemplares do Progresso do Tocantins conservados na sede do Progresso em Imperatriz, com o intuito de identificar as "marcas" editoriais do jornal.

\footnotetext{
${ }^{4}$ GODINHO, Sergio Antonio. Sergio Antonio Godinho: Entrevista [fev. 2019]. Entrevistadora: Thays Assunção Reis. Imperatriz: Jornal O Progresso, 2019.

${ }^{5}$ NATHASJE, Illya. Illya Nathasje: Entrevista [fev. 2019]. Entrevistadora: Thays Assunção Reis. Imperatriz: Jornal O Progresso, 2019.
} 


\section{O Progresso: aspectos históricos}

O primeiro editorial do jornal O Progresso do dia 03 de maio de 1970 evidencia o marasmo econômico de Imperatriz antes da rodovia Belém-Brasília e demonstra a expectativa de desenvolvimento e crescimento da cidade com a construção desse empreendimento.

Chegamos até aqui que não é ainda a nossa meta. É nossa aspiração fazer deste noticioso um instrumento a serviço da coletividade de que somos parte. E que através de "O PROGRESSO" possa a voz de Imperatriz fazer-se sentir em outros rincões, levando até êles a demonstração da pujança desta terra querida que dia a dia desperta para novos rumos e novos empreendimentos, estuante de vida, marco de transição entre o marasmo que ficou sufocado pelas máquinas que rasgaram a Belém-Brasília e os horizontes que se descortinaram ante os olhos de uma geração que surge (NOSSSA CAMINHADA, 03 maio 1970, p. 01).

No decorrer dos anos, O Progresso passa por uma série de modificações no formato e na administração. Conforme Sanches (2002), no ano de 1975 o jornal O Progresso é adquirido pelo empresário Sérgio Antônio Nahuz Godinho, passa a ter uma circulação diária - de terça a domingo - e triplica o número de páginas, sendo composto por 12 páginas. O autor acrescenta:

Após Jurivê, outros editores imprimiram sua marca e estilo nas páginas do jornal e na história cotidiana da cidade, entre eles: Hiroshy Bogéa, Adalberto Franklin, Antônio Costa, Luiz Duarte e, atualmente, Coriolano (Coló) Filho, que pela segunda vez está à frente da redação (SANCHES, 2002, p. 174).

Ao observar exemplares do jornal O Progresso da década de 1980, foi constatado um tom mais cultural. Proliferam nas páginas do impresso os espaços destinados à cultura de Imperatriz e é criado o caderno especial de domingo $O$ Progressinho. Esse caderno era composto de histórias em quadrinhos e produções culturais da cidade.

A empresa funciona, desde 2012, em um prédio cedido por um de seus sócios, localizado na rua Amazonas, $n^{\circ} 55$, bairro Centro. A redação do diário possui uma equipe enxuta, composta por um editor-chefe, dois repórteres e uma revisora. Além desses, há três diagramadores responsáveis pela montagem do jornal. Os profissionais são todos contratados com carteira assinada, sendo que os repórteres trabalham cinco horas diárias e o editor-chefe, revisor e diagramadores cumprem seis horas.

Resgatamos aqui o relato do empresário e diretor-proprietário José Matos Vieira (2008), sobre o registro dos primeiros integrantes do jornal: 


\begin{abstract}
Uma equipe era composta de jornalistas aqui da terra e outros vindos de outras partes do país, aqui de passagem ou de férias. Foram eles: Pedro Pereira Braga, excelente cronista, Dorian Ricker, Teles de Menezes e Luiz Henrique Veras, os maiores incentivadores para a criação desse jornal; Antônio Rodrigues Filho (odontólogo), Edmilson Franco (advogado), Adelman Costa (radialista), José Edílson Fialho (colunista social), Cézar Jansen Pereira (funcionário público), Sidney Valadares Vieira (economista, falecido), Sérgio Macedo (empresário), Humberto Nunes (advogado no estado do Piauí), Dr. Aureliano Neto (advogado, hoje juiz de direito), Dr. Agostinho Noleto, Sálvio Dino, Dr. Édson Vidigal (que manteve a coluna do Vidigal) por muito tempo, Dr. Clemente Viegas (advogado), professor José Queiroz, de Carolina; e ainda João Correia Rocha e Mário Mazzini, de Marabá, hoje falecidos; Otávio Barros, o primeiro a trabalhar contratado como repórter; depois Helius de Monção e Vitor Hugo, vindos de Goiânia; José Pitta, de Brasília, e Flavio Góes, do Rio de Janeiro. Estes foram os jornalistas e colaboradores que ajudaram a dar vida a "O PROGRESSO" até 1975, enquanto eu estive no comando (VIEIRA, 2008, p. 127).
\end{abstract}

O Progresso, como o próprio slogan sugere "expressão regional”, alcança 11 cidades para além de Imperatriz. São oito localidades do Maranhão (Carolina, Porto Franco, João Lisboa, Estreito, Balsas, Governador Edison Lobão, Cidelândia e Ribamar Fiquene) e três do Tocantins (Augustinópolis, Sítio Novo do Tocantins e Tocantinópolis), segundo informações repassadas pelos gestores do veículo.

Como principal jornal impresso da cidade de Imperatriz, o veículo tem sido alvo de estudo desde as primeiras monografias do curso de Jornalismo da Universidade Federal do Maranhão, campus de Imperatriz. De acordo com levantamento feito pelo Grupo de Pesquisa Jornalismo, Mídia e Memória, entre 2011 e 2016, onze trabalhos de conclusão de curso foram apresentados tendo como referência $O$ Progresso, todavia, os trabalhos utilizam o impresso, na maioria das vezes, apenas como fonte de pesquisa. A título de exemplo, a monografia de Jeferson Rodrigues Borges, intitulada "Jornalismo policial no jornal impresso: a construção das notícias da editoria de polícia do jornal O Progresso", defendida em 2011, inaugura uma perspectiva de trabalho que estuda o jornal não pelo viéis histórico, mas como fonte de pesquisa.

Nesse sentido, observamos $O$ Progresso sendo utilizado fundamentalmente como fonte de pesquisa para explicar: como a cidade de Imperatriz foi caracterizada como capital nacional da pistolagem; quais os dilemas do jornalismo cultural; como o jornal enfrentou o período da ditadura; como foi a cobertura sobre a cassação do governador Jackson Lago; como o impresso construiu o discurso do estado do "Maranhão do Sul”; quais as narrativas sobre a demonização 
do MST; quais os discursos sobre a violência doméstica e a Lei Maria da Penha; quais representações sobre as doenças psiquiátricas e homossexualidade no veículo, entre outras pesquisas na mesma perspectiva. O trabalho que se aproxima da parte histórica é o intitulado: "Imprensa em Imperatriz - MA: uma proposta de periodização dos jornais impressos (1932 2010)" de Thays Assunção. Nessa monografia, a autora conta aspectos de vários impressos da cidade, entre eles, O Progresso.

Em que pese a necessidade de contar mais profundamente a história do veículo em Imperatriz, encontramos rastros sobre os avanços da empresa jornalística em outra localidade, uma história até então desapercebida e ao mesmo tempo importante para entendimento das motivações para fundação de um jornal à época. Trata-se de uma empreitada regional, de um capítulo além das terras maranhenses.

\section{Como se situa o jornalismo regional}

O jornalismo regional, também conhecido como do interior, caracteriza-se por apresentar uma "maior proximidade geográfica em relação aos fatos que reportam, com os leitores que privilegiam e com as fontes às quais dão voz" (AGUIAR, 2016, p. 17). Por isso, a proximidade é apontada como o elemento distintivo da prática jornalística desenvolvida fora dos grandes centros urbanos.

A proximidade, no entender de Fernandes (2013), é um dos critérios de noticiabilidade mais fortes na produção jornalística do interior, visto que a força integrativa e identitária dos veículos das cidades de pequeno e médio porte está na notícia de proximidade. Diz o autor:

Para um profissional atuante no jornal do interior, a proximidade, associada à atualidade, prevalece no momento de seleção de uma notícia. Depois se agregam outros elementos, como importância, tamanho etc. Uma notícia sobre alguma medida tomada pelo governo federal pode ser atual, importante e se enquadrar nas medidas disponíveis na página, mas será descartada se não tiver um elemento de interesse estritamente local (FERNANDES, 2013, p. 115).

Dornelles (2010) compartilha do mesmo entendimento, ao afirmar que a proximidade é um dos elementos da notícia mais importantes para a imprensa do interior. Ela "trata de comunicar conteúdos considerados pertinentes aos seus leitores com o objetivo de conseguir a fidelização dos públicos” (DORNELLES, 2010, p. 239). É por isso que os periódicos 
interioranos priorizam em suas páginas as informações locais que despertam rapidamente o interesse dos moradores que residem na cidade-sede do veículo.

Além da proximidade presente nas notícias, alguns autores entendem o jornalismo regional a partir da área de atuação dos veículos. É o caso do geógrafo Santos (1955[2007]), que classificou o jornal regional como aquele capaz de circular e atender uma respectiva área territorial. Bueno (2013, p. 45-46) também compartilha do mesmo entendimento, ao afirmar que o jornal regional objetiva exercer sua influência "numa determinada região, abarcando, portanto, com sua circulação e cobertura, algumas cidades ou municípios".

Avançando nesse debate, Pinto (2015) apresenta uma subdivisão da mídia regional brasileira baseada em três escalas de estudo: a) Supraestaduais - formadas por grupos ou veículos de mídia cuja atuação ultrapassa os limites do estado de origem; b) Estaduais agregam grupos ou veículos cujas atuações coincidem com os limites do estado; c) Subestaduais - compostas por veículos e ou grupos de abrangência mais restrita, com cobertura pontual em alguns municípios.

Nessa mesma direção, Aguiar (2016) classifica os jornais regionais brasileiros em três tipos: a) Regional-supraestadual - são grupos de mídia cuja atuação ultrapassa os limites do seu estado de origem para estados contíguos, seja por meio da propriedade de veículos ou parcerias em diferentes localidades; a) Regional-estadual - representam os grupos sediados em capitais de estados que possuem pelo menos um título de jornal com circulação na maior parte do território estadual; c) Regional-subestadual - corresponde aos grupos que possuem pelo menos um título de jornal sediado em uma região metropolitana fora da capital do estado ou em uma cidade-polo de região econômica reconhecida.

Por sua vez, Deolindo (2016) compreende a regionalização dos veículos jornalísticos em três camadas estreitamente relacionadas: a) área de cobertura jornalística - aquela em que os jornalistas mais frequentemente realizam reportagens; b) a área de negociação publicitária corresponde aos espaços em que estão localizados os anunciantes habituais de determinada mídia; e c) a área de circulação ou alcance - refere-se aos locais em que os veículos estão presentes.

A autora ainda explica que, no caso dos jornais impressos, a área de circulação é a mais ampla, a área potencial de exploração de receitas é menor do que a primeira, e a área de 
reportagem fica restrita prioritariamente à cidade sede do jornal. Já os sites de notícias exibem uma área de alcance mais abrangente e "uma área de apuração mais ampla do que a de exploração de receitas, visto que o mercado é altamente localizado" (DEOLINDO, 2016, p. 270) e as notícias não se limitam à cidade em que o portal está sediado.

Ao tratar da função do jornalismo regional, Deolindo (2013) afirma que ele preenche a lacuna de informação deixada pela prática jornalística nacional e estadual referente à multiplicidade de acontecimentos que ocorrem no país. Os jornais regionais e locais, juntamente com os portais de notícias regionais, "publicam notícias de interesse direto e próximo da comunidade, ao mesmo tempo em que reproduzem informações dos grandes centros para manter o público informado do que se passa [lá fora]" (DEOLINDO, 2013, p. 7-8).

Dialogando com essa perspectiva, Dornelles (2004, p. 132) afirma que o jornalismo do interior é muito mais comportamental do que estrutural, sendo guiado por uma "política de vizinhança, a solidariedade, o coletivismo, os valores, a moral, a fé religiosa, o respeito humano e a cultura de pequenas populações". Além disso, a filosofia editorial dos jornais é comunitária, ou seja, tem como objetivo central a produção de matérias que atendam aos anseios e reivindicações da comunidade.

A partir dessa leitura, percebe-se que o jornalismo regional se configura como uma prática que extrapola os limites territoriais da sede dos seus veículos e alcança outras localidades, seja pela sua cobertura, presença, captação de receitas ou mesmo publicação de conteúdo. Além do mais, ele permite que cidades pequenas, desprovidas de meios de comunicação tradicionais ou outros canais de informação, tenham acesso a notícias sobre seu próprio cotidiano e da sua região. Esse é o caso em que se insere a história do Progresso do Tocantins, história que será contada no tópico seguinte.

\section{A experiência com o jornal $O$ Progresso do Tocantins}

O jornal O Progresso do Tocantins tinha veiculação semanal na cidade de Araguaína. A primeira edição é referente aos dias 30 de julho a 5 de agosto de 1990. De maneira particular, olhar para essa primeira edição torna-se estratégico para entender os rumos que o próprio jornal fala de si como proposta de jornalismo. Assim, temos na capa da edição $n^{\circ} 1$ um editorial com o título "Bom Dia, Tocantins". Nele, o impresso introduz noções de cidadania, falando sobre 
direitos e deveres e sinalizando a existência de políticos que estratificam esses direitos em função de interesses próprios. Nesse caminho, o jornal se coloca como intermediador e vigilante dos direitos do cidadão:

É nessa luta diuturna e constante, em defesa desses inalienáveis direitos da pessoa humana, especialmente o cidadão comum, que a imprensa, como um todo, deveria se integrar. Infelizmente, em muitas ocasiões isso não ocorre.

E, para juntar-se a esse cidadão sofrido e desamparado para lutar por seus direitos, para contestar o Poder Público quando este for desviado da sua verdadeira função - que é a de servir exclusivamente ao povo, e não aqueles que o representam - que O PROGRESO DO TOCANTINS começa a sua caminhada em terras tocantinenses (BOM DIA..., 30 jul. a 05 ago. 1990, p. 01).

Além do discurso apresentado no editorial, outras motivações levaram a implantação do tradicional jornal de Imperatriz com outra roupagem para a cidade de Araguaína. Segundo o proprietário do jornal O Progresso, Sérgio Antonio Godinho (2019), o contexto político e econômico da época apresentava a cidade de Araguaína como um local profícuo para a instalação de um impresso, pois no final da década de 1980 havia dúvida sobre onde seria a capital do novo estado. A aposta do empresário era que Araguaína seria a sede do governo do Tocantins. Por isso, ele começou a articular a criação do impresso no município. Porém, Palmas foi escolhida para ser a capital do Tocantins logo após uma experiência inicial de instalação da sede do Governo Estadual em Miracema (TO). Não havia condições econômicas e nem viabilidade a curto prazo para inaugurar um jornal impresso em uma localidade que começava literalmente a ser arquitetada, em que havia poucos moradores. Dessa forma, foi mantida a ideia de iniciar o trabalho em Araguaína como havia sido previsto. Além do mais, esse município tocantinense era o mais desenvolvido da época próximo de Imperatriz, onde o jornal era impresso. Em outras palavras, o Progresso do Tocantins foi fundado devido à divisão do estado do Goiás, oportunidade vista pela direção do veículo do Maranhão para levar a expertise de 20 anos em terras maranhenses para o Tocantins e liderar a corrida jornalística no novo estado.

Voltando à edição $\mathrm{n}^{\mathrm{o}} 1$, observa-se a seguinte manchete: "Preso estuprador de menor" e outras duas chamadas de capa: "IBAMA cadastra moto-serras" e "Norte-Sul é necessária para o progresso do Tocantins”. Destaca-se que, naquela época, abaixo dos títulos de capa, havia bastante texto, ou seja, muitas matérias já apareciam na íntegra na primeira página. Pelo teor do conteúdo dessa semana, percebe-se o jornal já se posicionando como inserido dentro da 
dinâmica da rotina de Araguaína e cidades vizinhas e articulando o próprio nome do veículo a títulos de matérias em uma tentativa de reforço da identidade.

Imagem 01 - Capas das duas primeiras edições de O Progresso do Tocantins, 30 jul. a 05 ago. 1990 e 06 ago. a 12 ago. 1990
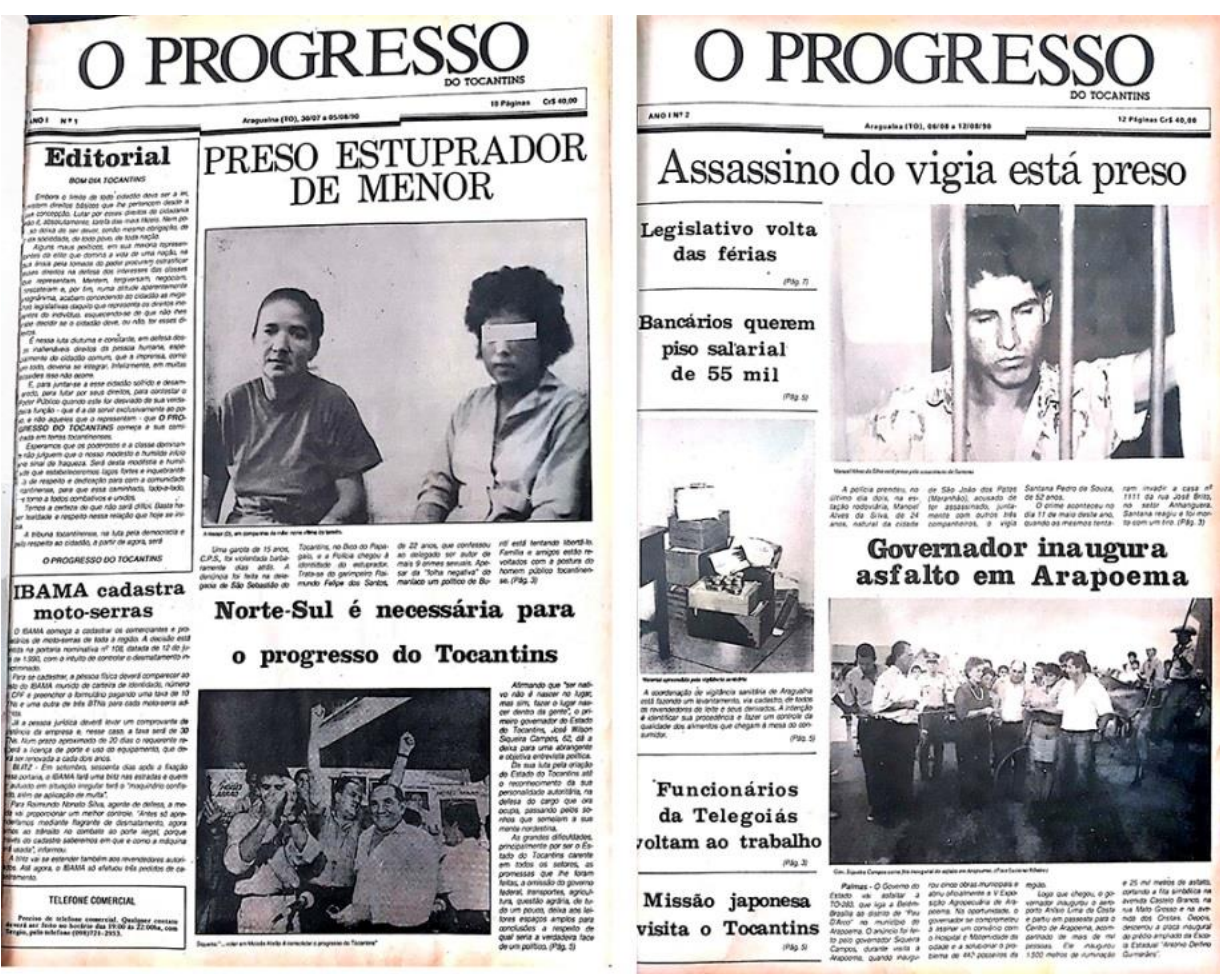

Fonte: Acervo do jornal O Progresso, em Imperatriz (MA).

Segundo dados do primeiro expediente, o veículo tinha como editor Reynaldo Cruzeiro, redatora Dalira Pereira de Souza e gerente comercial Mônica Costa Melo. Observando a primeira edição, é possível encontrar outros nomes: Helder Peixoto, atuando como colunista; Ferdinando Campos de Mello, colaborando com artigo na editoria de opinião; Illya Nathasje, entrevistando o governador Siqueira Campos; Cida, com a coluna "Em Sociedade"; Marcelo e Humberto assinando charges sobre fábricas no Tocantins e Juredo com coluna sobre assuntos gerais. Desses nomes, podemos certificar que Juredo tratava-se do pseudônimo de Jurivê de Macedo, um dos fundadores do jornal O Progresso de Imperatriz, mas nascido em Porto Nacional, então Goiás. Ele faleceu em 2010, deixando uma rica trajetória de livros e histórias, considerado um dos maiores jornalistas de Imperatriz. Por sua vez, Illya Nathasje continua atuante no veículo do mesmo grupo, que hoje tem filial apenas em Imperatriz, no Maranhão. 
Não foram obtidas mais informações sobre os outros nomes, visto que as entrevistas realizadas buscaram aprofundar em questões mais estruturais do veículo, tendo em vista que até o o ano de 2021 não havia qualquer informação documentada sobre esse capítulo da história do Progresso.

O jornal possuía 10 páginas contendo editorias, como Opinião, Cidade, Entrevista, Memória, Diversão e Lazer e Estado. Era preto e branco, com poucas fotografias e muito texto. O jornal na nova cidade seguiu os passos de buscar uma "expressão regional", assim como ocorria em Imperatriz. Por isso, é perceptível matérias de várias cidades do interior ao redor de Araguaína. Nota-se a proximidade geográfica, conforme sinaliza Aguiar (2016), como critério de noticiabilidade de $O$ Progresso do Tocantins. Por exemplo, na edição $\mathrm{n}^{\circ} 2$ de 06 a 12 de agosto de 1990, o jornal traz na capa a chamada "Governador inaugura asfalto em Arapoema", noticiando a realidade de uma cidade pequena a $146 \mathrm{~km}$ de Araguaína. Talvez haja quem considere a cidade acima nem tão próxima assim, porém, outros critérios atuam para ela ser contida na área de cobertura de O Progresso do Tocantins, como o desejo desse veículo de abarcar e influenciar municípios, realidade semelhante à verificada por Bueno (2013) em outros estados.

Sobre a rotina do veículo, o proprietário Sérgio Antonio Godinho (2019) conta que o impresso enfatizava mais as notícias do fim de semana, e ele mesmo lia a versão final do jornal, enviando-o em seguida por ônibus para Araguaína. Ou seja, o jornal tinha equipe em Araguaína com sede, porém, a parte de diagramação e finalização era realizada em Imperatriz.

Eles faziam a matéria lá e mandavam pelo ônibus, naquela época não tinha internet, vinha pelo ônibus tudo, tudo escrito datilografado. Não tinha computador não. As matérias vinham pela Transbrasiliana durante a semana, praticamente todo dia vinha as matérias de lá e o jornal era impresso aqui (GODINHO, S. A., 2019).

Em tempos em que o jornal impresso perde força diante dos avanços da internet e das imensas possibilidades de comunicação e deslocamento de notícias, o relato é um registro de um período em que o impresso vencia as distâncias geográficas e econômicas por ser referencial diante da escassez de informações. De acordo com Godinho (2019), na trajetória do jornal até 1997, o número de páginas variou entre 8 e 12 páginas e, com a implantação do fax na sede do veículo em Araguaína, ficou mais ágil o envio de matérias para Imperatriz. No total, eram 
impressos 2.000 mil exemplares, que eram distribuídos em órgãos e vendidos em bancas. O material que não era vendido era entregue dois dias depois à população gratuitamente, como estratégia do veículo de fazer nome e auto divulgar-se. O proprietário relembra ainda que nunca foi estratégia da direção tornar $O$ Progresso do Tocantins diário, justamente por ele estar integrado em uma cidade menor que Imperatriz, o que rendia pouco assunto.

Em entrevista com o proprietário Godinho, constatou-se o quanto é difícil encontrar fontes para recontar a história do veículo, pois a maioria da equipe morava em Araguaína. Illya Nathasje é uma das referências porque continua atuando no Progresso de Imperatriz e participou das atividades em Araguaína:

Em Araguaína eu ia lá toda semana, eu tentava fazer o comercial de lá daqui. O Adalberto Franklin cuidou um bom tempo para gente em Araguaína. Nós tivemos um problema que a Dalira que era nossa editora lá, ela era do Mato Grosso, resolveu voltar e aí o Adalberto ajudou a gente lá um tempo (NATHASJE, 2019).

Nesse trecho, Illya Nathasje lembra de Adalberto Franklin, historiador e jornalista de Imperatriz, falecido em 2017, personagem importante da cena imperatrizense que contribuiu também para o avanço da imprensa da cidade vizinha. Illya Nathasje também contou como o jornal com sede em Araguaína tornou-se referência para a região e lugar de embates políticos. Segundo ele, Joaquim de Lima Quinta foi interventor na Prefeitura de Araguaína, nomeado pelo governador Siqueira Campos. Todavia, o interventor concedeu entrevista ao jornal na qual declarou que "eu estou interventor, mas não devo o cargo ao Siqueira, se ele quiser o cargo é dele, ele pode me tirar a hora que quiser" (NATHASJE, 2019). O trecho recebeu destaque na capa e chegou ao conhecimento do governador, que, no dia seguinte à publicação, estava em Araguaína, destituindo o interventor. No site da Câmara Municipal de Araguaína (PREFEITOS, 2020) consta que Joaquim de Lima Quinta atuou como interventor entre 02 de abril e 25 de novembro de 1990. Mais do que aprofundar-se nesse acontecimento, pretende-se aqui sinalizar a importância da articulação política do veículo para todo o estado, motivo esse que ironicamente levaria ao fim do veículo.

Segundo Sergio Antonio Godinho (2019), em 1997 o grupo conseguiu vislumbrar boas motivações para fundar um jornal diário em Palmas. Era a oportunidade de solidificar-se na capital do mais novo estado do Brasil, conforme sonhara no início da década de 1990. As 
relações políticas e econômicas com o Governo do Estado e o já avançado desenvolvimento estrutural da cidade facilitaram a instalação de uma nova sede de O Progresso em Palmas. Mas foi justamente essa decisão que levou o jornal O Progresso do Tocantins a seu encerramento em Araguaína. De acordo com Godinho (2019), não era possível manter financeiramente dois jornais naquele momento, tendo escolhido, portanto, fundar o Diário Tocantinense no ano de 1997.

O nome do jornal em Palmas era Diário Tocantinense, não quis manter o mesmo nome [...] Comprei máquinas, estruturei o jornal lá todinho. Comprei máquina, impressora, computadores, tinha uma sede, contratei jornalistas formados. Equipe, subeditora, três repórteres, colunista social, dois diagramadores, na parte de oficina tinha quatro pessoas. Uma faixa de umas doze pessoas (GODINHO, S. A., 2019).

Esse novo capítulo do avanço do jornal maranhense por terras tocantinenses teve breve duração. Em 1999 o veículo foi vendido por Sergio Godinho, que decidiu retornar para Imperatriz e dedicar-se exclusivamente ao jornal local. Atualmente, a ligação do jornal $O$ Progresso em Imperatriz com o estado do Tocantins se dá por meio de uma editoria intitulada “Tocantins”, na qual são veiculadas notícias de Araguaína e cidades vizinhas.

\section{Novas direções}

Acredita-se que com este trabalho foi esclarecido um capítulo não registrado sobre a história do diário mais antigo da cidade de Imperatriz: a expansão dele em terras tocantinenses, especificamente em Araguaína. Isso demonstra a estratégia jornalística do grupo que fincou laços no Maranhão e ousou realizar o mesmo trabalho no estado vizinho. Nota-se também como a situação geográfica, política e econômica pode interferir na fundação de um veículo e que a aposta no momento e lugar certo pode resultar na permanência do meio. Acredita-se que, se desde o princípio a iniciativa tivesse ocorrido na cidade de Palmas (TO), talvez hoje haveria um grupo consolidado nessa capital.

Considera-se também que a existência de O Progresso do Tocantins em Araguaína foi um vetor potente na comunicação daquela cidade, atraindo a atenção de políticos e investidores para o olhar do veículo sobre a região. Por lá, durante sete anos, semanalmente, apesar das 
dificuldades para impressão, o jornal circulou sem interrupção, buscando cumprir o papel que levantou no primeiro editorial: a defesa dos direitos dos cidadãos.

Além disso, o veículo foi caracterizado como de expressão regional, porque atendeu durante a sua circulação os critérios de Deolindo (2016), como a definição das áreas de cobertura e exploração de receitas, além de preencher a lacuna com informações de interesse daquela região, objetivo que não cabia ao jornal com sede no território maranhense.

Por meio deste artigo não foi possível registrar toda a história e pormenores da trajetória desse veículo, e nem esta foi a proposta deste trabalho, porém, deixa-se aqui os primeiros indícios de uma história que necessita ser reconstruída por diversos ângulos de pesquisa. Todas as edições de $O$ Progresso do Tocantins estão encadernadas e guardadas na sede do jornal $O$ Progresso em Imperatriz, prontas para serem consultadas. Pesquisadores de todas as áreas podem ali encontrar uma fonte rara para entender parte da história política, econômica e social de Araguaína; os principais embates políticos durante os primeiros anos do novo estado do Tocantins; a rotina de produção de um jornal daquela época; a atuação dos jornalistas e toda equipe envolvida no veículo; e a relação entre os dois estados mediada em muitos momentos pelo próprio veículo.

\section{Referências}

AGUIAR, Sonia. Territórios do jornalismo: geografias da mídia local e regional no Brasil. Petrópolis: Vozes; Rio de Janeiro: Editora PUC-Rio, 2016.

BOM DIA, Tocantins. O Progresso do Tocantins, Araguaína, ano 1, n. 1, p. 1, 30 jul. a 05 ago. 1990.

BUENO, Wilson da Costa. Jornal do interior: conceitos e preconceitos. In: ASSIS, Francisco de (org.) Imprensa no interior: conceitos e contextos. Chapecó: Argos 2013. p. 45-65.

CARVALHO, Rhaysa Novakoski. O desenho de uma trajetória: design editorial nos jornais diários de Imperatriz (MA), de 1979 a 2013. 2016. Monografia (graduação) - Universidade Federal do Maranhão, Imperatriz, 2016

DEOLINDO, Jacqueline da Silva. Cidade e indústrias de mídia: distinções entre metrópole e interior. In: SIMPÓSIO NACIONAL DE GEOGRAFIA URBANA, 13.,. 2013, Rio de Janeiro. Anais [...], Rio de Janeiro: Uerj, 2013. 
DEOLINDO, Jacqueline da Silva. Regiões jornalísticas: uma abordagem locacional e econômica da mídia do interior fluminense. 2016. Tese (doutorado) - Universidade Estadual do Rio de Janeiro, Rio de Janeiro, 2016.

DORNELLES, Beatriz. Jornalismo comunitário em cidades do interior: uma radiografia das empresas jornalísticas: administração, comercialização, edição e opinião dos leitores. Porto Alegre: Sagra Suzzato, 2004.

DORNELLES, Beatriz. Localismo nos jornais do interior. Revista Famecos, Porto Alegre, v. 17, n. 03, 2010. Disponível em:

http://revistaseletronicas.pucrs.br/ojs/index.php/revistafamecos/article/view/8191. Acesso em: 09 jan. 2018.

NOSSA caminhada. O Progresso, Imperatriz, ano 1, n. 1, 03 maio 1970, p. 01. Disponível em: http://www.joimp.ufma.br/img/acervo/aac30d87c2ce314d8604fa48cf96bcc0.pdf. Acesso em: 11 set. 2020.

FERNANDES, Mario Luiz. A proximidade como valor-notícia na imprensa do interior. In: ASSIS, Francisco de (org.). Imprensa do interior: conceitos e contextos. Chapecó: Argos, 2013. p. 103-136.

FRANKLIN, Adalberto. Apontamentos e fontes para história econômica de Imperatriz. Imperatriz: Ética, 2008.

GODINHO, Sergio Antonio. Sergio Antonio Godinho: Entrevista [fev. 2019].

Entrevistadora: Thays Assunção Reis. Imperatriz: Jornal O Progresso, 2019.

GOVERNADOR inaugura asfalto em Arapoema. O Progresso do Tocantins, Araguaína, ano 01, n. 02, 06 a 12 ago. 1990.

NATHASJE, Illya. Illya Nathasje: Entrevista [fev. 2019]. Entrevistadora: Thays Assunção Reis. Imperatriz: Jornal O Progresso, 2019.

PINTO, Pâmela Araújo. Mídia regional brasileira: características dos subsistemas midiáticos das regiões Norte e Sul. 2015. Tese (doutorado) - Instituto de Arte e Comunicação Social, Universidade Federal Fluminense, Niterói, 2015. Disponível em: https://ppgcom.uff.br/wpcontent/uploads/sites/200/2020/03/tese_doutorado_2015_pamela_araujo.pdf. Acesso em: 29 set. 2020 .

PREFEITOS, 2020. Câmara Municipal de Araguaína. Disponível em: http://araguaina.to.leg.br/municipio/prefeitos/. Acesso: 25 jul.2021

REIS, Thays Assunção. História da Imprensa em Imperatriz-MA (1930-2010). EDUFMA, 2018. 
SANCHES, Edmilson. Imprensa escrita. In: Imperatriz: 150 anos. Imperatriz: Academia Imperatrizense de Letras, 2002. p. 167-179.

SANTOS, Milton. Classificação funcional dos jornais brasileiros - as regiões jornalísticas (1955). Noticiários da Rede Alcar, ano 7, n. 83, nov. 2007.

VIEIRA, José Matos. Lutas, fracassos e vitórias. Memórias. Imperatriz: Ética, 2008.

Submetido em: 24.06.2020.

Aprovado: 28.12.2021. 